\title{
Kontribusi Koperasi Karya Bhakti Mandiri Terhadap Usaha Ternak Ayam Kampung Pedaging di Kecamatan Bengalon Kabupaten Kutai Timur
}

\author{
Istikomah $^{1}$ dan Juraemi ${ }^{2}$ \\ ${ }^{1}$ Program Studi Agroteknologi, STIPER Kutai Timur \\ ${ }^{2}$ Program Studi Agribisnis, Universitas Mulawarman \\ 1Email: istikomah@stiperkutim.ac.id
}

\begin{abstract}
This study aims were to analyze the contribution of the KBM Cooperative for development of native chicken livestock business in the Bengalon district East Kutai Regency. The study was conducted in June-August 2019. Non parametric statistical research qualitative methods were used Chi Square tests and Rank Spearman Correlation. Explanatory research was used to explain the causal relationship between role variables and business development through testing hypotheses Chi Square test and Spearman Correlation. The contribution of the $K B M$ was calculated from the coefficient of determination. Sampling of respondents were taken from active cooperative members who carried out intensive of native chicken livestock business, taken by total sampling of 50 people with questionnaire instruments that had been tested for validity and reliability. The role of the KBM Cooperative had an average of 52\% or in the medium category, the development of chicken farming by KBM cooperatives was on average $60 \%$ in the high category. There was relationship between the role of the KBM Cooperative on the development of native chicken livestock business the result of Chi Square test $X^{2}$ count $=31.290$ compared to $X^{2}$ table $(\alpha=0.05)=9.488$, Relationship was in the strong category $\left(r_{s}=0.748\right)$. The contribution of KBM was $55 \%$ contributed for development of native chicken livestock business in the Bengalon district

Keyword: Contribution, Cooperative, Native Chicken Livestock Business, Chi Square, Rank Spearmans
\end{abstract}

\begin{abstract}
ABSTRAK
Penelitian ini bertujuan menganalisis kontribusi Koperasi KBM terhadap pengembangan usaha ternak ayam kampung pedaging di Kecamatan Bengalon Kabupaten Kutai Timur. Penelitian dilakukan bulan Juni-Agustus 2019. Metode penelitian kulitatif statistik non parametrik Uji Chi Square dan Korelasi Rank Spearmans. Explanatory research digunakan untuk menjelaskan hubungan kausal antara variabel peranan dengan pengembangan usaha melalui pengujian hipotesis Uji chi Square dan Korelasi Rank Spearmans. Kontribusi Koperasi KBM dihitung dari besarnya koefisien determinasi. Pengambilan sampel responden ialah anggota koperasi aktif yang sudah melalukan usaha ternak ayam kampung pedaging secara intensif diambil secara total sampling sebanyak 50 orang dengan instrumen kuesioner yang telah diuji validitas dan reliabilitas. Peranan Koperasi KBM rata-rata $52 \%$ atau termasuk kategori sedang, pengembangan usaha ternak ayam kampung yang dilakukan Koperasi KBM rata-rata $60 \%$ berada pada kategori tinggi. Terdapat hubungan yang erat antara Peranan Koperasi KBM terhadap pengembangan usaha ternak ayam pedaging di Kecamatan Bengalon hasil analisis uji Chi Square $X^{2}$ hitung $=31.290$ dibandingkan $X^{2}$ tabel $(\alpha=0.05)=9.488$ berpengaruh signifikan $Z_{\text {hitung }}=5,236$ dibandingkan $Z_{\text {tabel }(\alpha=0.5)}=1,645$ Keeratan hubungan berada pada kategori kuat $\left(r_{s}=0.748\right)$. Kontribusi Koperasi KM sebesar $55 \%$ berkontribusi terhadap pengembangan usaha ternak ayam kampung pedaging di Kecamatan Bengalon.
\end{abstract}

Kata kunci: Kontribusi, Koperasi, Usaha Ternak Ayam Kampung, Chi Square, Rank Spearmans 


\section{Pendahuluan}

Ayam kampung adalah plasma nutfah lokal Indonesia yang harus dijaga dan dilestarikan. Upaya pelestarian yang dapat dilakukan diantaranya ialah dengan membudidayakan ayam kampung secara intensif. Kecamatan Bengalon merupakan satusatunya kecamatan di luar Pulau Jawa yang pernah menjadi juara I Nasional Manajemen Usaha Kelompok Peternak Ayam Lokal Indonesia oleh Kementerian Pertanian Republik Indonesia tahun 2015 pada peringatan Bulan Bhakti Peternakan dan Kesehatan Hewan di bulan Oktober 2015. Penghargaan diberikan karena pola pemeliharaan intensif yang higienis dengan pemberian pakan yang sehat serta ramuan jamu herbal.

Ayam kampung termasuk diantara salah satu ternak unggas yang tinggi di Kabupaten Kutai Timur terutama di Kecamatan Bengalon. Populasi ayam kampung di Kecamatan ayam kampung (native chicken) BPS pada tahun 2015 berjumlah 29.303 ekor mengalami peningkatan pesat tahun 2017 berjumlah 114.726 ekor (BPS Kutai Timur, 2018). Peluang usaha semakin berkembang namun banyak kendala dan permasalahan krusial yang harus dihadapi. Input faktor produksi DOC sangat tergantung dari pasokan luar daerah yaitu Pulau Jawa karena belum mampu memproduksi sendiri, selain itu input pakan pabrik yang digunakan harganya fluktuatif (cenderung naik). Banyak kendalakendala lain dalam hal ketersediaan saprodi/sapronak, pemeliharaan hingga pengolahan dan pemasaran produk namun petani memiliki minat dan berkonsentrasi, siap bersaing, percaya diri serta keuletan dalam bekerja, meskipun masih membutuhkan bimbingan dalam pengembangan usaha ternak ayam kampung. Hal inilah yang menjadikan alasan penting dibutuhkannya suatu lembaga yang mewadahi/menampung permasalahan dan mencarikan solusi sehingga kesejahteraan petani/peternak meningkat. Lembaga yang tepat untuk mewadahi ekonomi kerakyatan ialah dalam bentuk lembaga koperasi.

Berdasarkan Undang-Undang No. 25 Tahun 1992, peran koperasi dalam perekonomian Indonesia ialah (1) Koperasi bisa berperan sebagai sarana untuk meningkatkan kesejahteraan masyarakat, (2) Sarana untuk meningkatkan penghasilan masyarakat, (3) Sebagai badan/lembaga usaha ekonomi yang mampu membuka lapangan kerja, dan (4) Berperan dalam upaya pemerintah mencerdaskan kehidupan bangsa (IKAPI, 2013). Pengembangan kelembagaan koperasi tidak lepas dari campur tangan pemerintah untuk menciptakan iklim kondusif sehingga dapat bersaing di pasar domestik dan ekspor (Wahyuningsih, 2007). Penguatan kapasitas kelembagaan melalui penguatan jejaring koperasi dengan mitra strategis merupakan kunci keberhasilan koperasi dalam meningkatkan usaha (Fitriani, 2015).

Pembangunan koperasi pertanian di era globalisasi dan kapitalisme adalah langkah panjang yang memerlukan proses penyadaran dan pembelajaran yang terusmenerus. Sastrawidjadja \& Adam (2015) mengadopsi dan mewujudkan sistem ekonomi 
konglomerasi koperasi melalui usaha-usaha besar dan bermacam-macam sehingga bisa melindungi kepentingan masyarakat lokal. Widjajani \& Hidayati (2014) membangun koperasi pertanian berbasis anggota dapat dilakukan dari bawah/masyarakat melalui (1) Meningkatkan pemahaman jati diri koperasi secara utuh (definisi, nilai-nilai dan prinsip), (2) Koperasi pertanian dan perkreditan dibangun dalam rangka mengembangkan ekonomi rakyat, (3) Membangun koperasi pertanian berdasarkan peta sosial ekonomi pedesaan, (4) Rancang bangun pola koperasi pertanian berbasis keanggotaan yang nyata, (5) Pengembangan koperasi pertanian dalam agrobisnis/agroindustri.

Sistem penerapan pertanian korporasi memiliki prospek yang baik untuk diaplikasikan pada koperasi. Pertanian korporasi merupakan kegiatan penggabungan lahan pertanian yang terorganisir bersama dari para petani dan terintegrasi dalam suatu manajemen tunggal. Sistem tersebut dapat menjadi solusi untuk banyak masalah yang dihadapi petani di masa sekarang. Standarisasi mutu, efisiensi dan efektivitas bisnis serta efisiensi pengelolaan pemanfaatan sumber daya bisa diharapkan ketika sistem pertanian perusahaan diterapkan. Menurut hasil analisis Musthofa \& Kurnia (2018) menunjukkan bahwa usahatani yang dilakukan melalui penerapan korporasi pertanian secara ekonomi meningkatkan pendapatan petani disertai adanya efektivitas pemakaian saprodi dan tenaga kerja, secara kelembagaan meningkatkan kemampuan SDM koperasi untuk bertransformasi dalam kelembagaan, dan secara sosial memudahkan petani dalam mengambil keputusan dan pertimbangan dalam menentukan keuntungan dan jenis pekerjaan.

Peran dan manfaatnya koperasi dapat diterima anggota dan masyarakat jika terdapat kesadaran dan kejelasan dalam hal keanggotaan koperasi (Heriyono, 2012). Koperasi harus mampu menunjukkan fungsi sebagai badan usaha di pedesaan dan pelaksana pemasaran produk agribisnis (Syahza \& Indrawati, 2010). Menurut Susilo (2013) bahwa peran koperasi agribisnis secara aktif telah dilibatkan dalam menjaga ketahanan pangan Indonesia lebih dari 30 tahun, namun setelah reformasi karena berubahnya peraturan maka perlu dilakukan revitalisasi internal maupun eksternal. Berdasarkan kajian Agustia et al., (2017) dalam mendukung petani kecil koperasi pertanian berperan penting. Peran kunci koperasi untuk mengembangkan akses pasar, meningkatkan posisi tawar petani (bargaining position), dan peningkatan kemampuan adopsi teknologi.

Arti kontribusi dari bahasa Inggris berasal dari kata contribute, contribution yaitu sumbangan, keikutsertaan maupun keterlibatan. Kontribusi dapat diberikan dalam berbagai bidang seperti finansial (keuangan), profesionalisme, ide pemikiran, kepemimpinan dan lainnya. Kontribusi Koperasi KBM yang dimaksudkan ialah 
sumbangan keterlibatan yang diberikan oleh Koperasi KBM kepada anggotanya yang memiliki usaha ternak ayam kampung pedaging kemudian dinilai dari segi sosial ekonomi.

Koperasi Karya Bhakti Mandiri (KBM) merupakan salah satu lembaga yang dibentuk dan diupayakan guna meningkatkan serta mengembangkan usaha ternak ayam kampung di Kecamatan Bengalon. Koperasi KBM berkontribusi sangat penting terutama sebagai sarana perekonomian dalam membantu penyediaan input produksi dan pelayanan yang dibutuhkan oleh para anggota dan masyarakat dalam pengembangan usaha ternak ayam kampung. Berdasarkan uraian tersebut maka diperlukan penelitian yang menganalisis kontribusi Koperasi KBM terhadap usaha ternak ayam kampung pedaging di wilayah Kecamatan Bengalon.

\section{Metode Penelitian}

Metode analisis pada penelitian menggunakan statistik kualitatif dengan alat analisis Rank Spearman (Statistik non parametrik Rank Spearman) menggunakan program software SPSS 23. Peran dan tingkat pengembangan usaha ternak yang dilakukan Koperasi KBM dikategorikan dalam 3 kelas interval skor (rendah, sedang, dan tinggi) dengan menggunakan skala Likert. Explanatory research digunakan untuk menjelaskan hubungan kausal antara variabel peran dengan pengembangan usaha melalui pengujian hipotesis Uji Chi Square dan Korelasi Spearman. Pengambilan sampel responden anggota koperasi aktif ditentukan secara survei sebanyak 50 orang yang sudah melakukan usaha ternak ayam kampung secara intensif dengan instrumen kuesioner telah diuji validitas dan reliabilitas. Uji Chi Square, Korelasi Rank Spearmans, dan validitas-reliabilitas menggunakan software SPSS 23. Pengambilan data dilaksanakan bulan Juni-Agustus 2019 di Kecamatan Bengalon. Tahapan analisis yang dilakukan:

\section{Skala Likert}

Skala Likert merupakan skala psikometrik yang dapat digunakan untuk mengukur persepsi, sikap atau pendapat orang/kelompok mengenai suatu fenomena sosial (Sugiyono, 2017). Skala Likert digunakan untuk mengetahui peran Koperasi KBM dan tingkat pengembangan usaha ternak ayam KUB di lokasi penelitian dengan skor 1 (rendah), 2 (sedang) dan 3 (tinggi). Hasil total skor dari instrumen penelitian (skala Likert) kemudian dibuat kelas interval. Kriteria penilaian peran Koperasi KBM pada Tabel 1 dan 2. 
Tabel 1. Skor penilaian peran koperasi

\begin{tabular}{clcc}
\hline No. & Indikator & Skor Minimum & Skor Maksimum \\
\hline 1 & Layanan penyediaan dan pengadaan saprodi & 2 & 6 \\
2 & Pembinaan dan pendampingan berkelanjutan & 4 & 12 \\
3 & Layanan jasa pengolahan dan pemasaran & 3 & 9 \\
4 & Wahana menjalin kerjasama & 1 & 3 \\
\hline & Total & 10 & 30 \\
\hline
\end{tabular}

Tabel 2. Skor pengembangan usaha ternak ayam kampung

\begin{tabular}{clcc}
\hline No. & Indikator & Skor Minimum & Skor Maksimum \\
\hline 1. & Meningkatkan permintaan produk & 2 & 6 \\
2. & Perbaikan sistem produksi & 2 & 6 \\
3. & Perbaikan pemasaran & 3 & 9 \\
\hline & Total & 7 & 21 \\
\hline
\end{tabular}

Kategori tersebut diukur dengan menggunakan rumus interval kelas Suparman (1995) yaitu:

$$
\mathrm{C}=\frac{\mathrm{Xn}-\mathrm{Xi}}{\mathrm{K}}
$$

$$
\begin{array}{ll}
\text { Keterangan: } & \mathrm{C}=\text { Interval kelas } \\
\mathrm{Xn}=\text { Skor maksimum } \\
\mathrm{Xi}=\text { Skor minimum } \\
\mathrm{K}=\text { Jumlah kelas }
\end{array}
$$

Berdasarkan skor maksimum dan minimum pada Tabel 1 dan 2, maka kelas interval adalah:

1. Peran Koperasi:

$$
C=\frac{30-10}{3}=6,67 \approx 7
$$

2. Pengembangan usaha ternak ayam kampung:

$$
\mathrm{C}=\frac{21-7}{3}=4,67 \approx 5
$$

Daftar distribusi frekuensi peran Koperasi KBM dapat dilihat Tabel 3.

Tabel 3. Distribusi Frekuensi Peran Koperasi KBM di Kecamatan Bengalon

\begin{tabular}{lcc}
\hline No. & Interval kelas & Peran Koperasi KBM \\
\hline 1. & $10-16$ & Rendah \\
2. & $17-23$ & Sedang \\
3. & $24-30$ & Tinggi \\
\hline
\end{tabular}

Sumber: Data primer diolah (2019)

Daftar distribusi frekuensi pengembangan usaha ternak ayam kampung dapat dilihat pada Tabel 4.

Tabel 4. Distribusi Frekuensi Pengembangan Usaha Ternak Ayam Kampung

\begin{tabular}{ccc}
\hline No. & Interval kelas & Pengembangan Usaha Ternak Ayam Kampung \\
\hline 1. & $7-11$ & Rendah \\
2. & $12-16$ & Sedang \\
3. & $17-21$ & Tinggi \\
\hline
\end{tabular}

Sumber: Data primer diolah (2019) 


\section{Uji Chi Square $\left(\mathrm{X}^{2}\right)$ dan Korelasi Rank Spearman $\left(\mathrm{r}_{\mathrm{s}}\right)$}

Keeratan hubungan Peran Koperasi KBM (PKBM) dengan Tingkat Pengembangan Usaha Ternak Ayam Kampung (PUTAK) di Kecamatan Bengalon dianalisis dengan tahapan:

1. Chi Square $\left(x^{2}\right)$

Chi Square $\left(X^{2}\right)$ digunakan untuk mengetahui ada atau tidaknya hubungan antara peranan Koperasi KBM terhadap pengembangan usaha ternak ayam kampung pedaging digunakan analisis Chi Square $\left(X^{2}\right)$ dengan rumus (Siegel, 2008).

$$
\mathrm{X}^{2} \text { hitung }=\sum_{i=1}^{r} \sum_{j=1}^{k} \frac{(O i j-E i j)^{2}}{E i j}
$$

Keterangan: $\mathrm{Oij}=$ Jumlah observasi baris ke-i pada kolom ke-j

Eij = Banyak kasus yang diharapkan di bawah Ho baris ke-i pada kolom ke-j

Kaidah keputusan:

Jika $X^{2}$ hitung $<X^{2}$ tabel $(\alpha=0,1)$ maka Ho diterima dan Ha ditolak

Berarti tidak ada hubungan antara peran koperasi dengan pengembangan usaha ternak ayam kampung pedaging.

Jika $X^{2}$ hitung $>X^{2}$ tabel $(\alpha=0,1)$ maka Ho ditolak Ha diterima

Berarti terdapat hubungan antara peran koperasi dengan pengembangan usaha ternak ayam kampung pedaging.

2. Korelasi Rank Spearman $\left(\mathrm{r}_{\mathrm{s}}\right)$

Korelasi Rank Spearman (rs) digunakan untuk mengetahui keeratan dan besarnya hubungan antara peran Koperasi KBM dengan pengembangan usaha ternak ayam kampung pedaging menggunakan Statistik non parametrik Korelasi Rank Spearman. Koefisien Korelasi Rank Spearman sebagai berikut (Siegel, 2008).

$$
r_{\mathrm{s}}=1-\frac{6 \sum_{i=1} d i^{2}}{N\left(N^{3}-1\right)}
$$

Keterangan: $\mathrm{r}_{\mathrm{s}} \quad=$ Koefisien Korelasi Rank Spearman

$\mathrm{N}=$ Jumlah sampel

di $=$ Selisih ranking

Tabel 5. Nilai dan Tingkat Korelasi

\begin{tabular}{llc}
\hline No & Nilai Korelasi $\left(\mathbf{r}_{\mathbf{s}}\right)$ & Tingkat Korelasi \\
\hline 1 & $0,00-0,199$ & Sangat lemah \\
2 & $0,20-0,399$ & Lemah \\
3 & $0,40-0,599$ & Cukup \\
4 & $0,60-0,799$ & Kuat \\
5 & $0,80-0,100$ & Sangat Kuat \\
\hline
\end{tabular}

Sumber: Siregar (2013) 


\section{Uji Z}

Uji Z digunakan untuk menguji signifikansi hubungan digunakan uji Z N >30 (Siregar, 2013). Rumus:

$$
\mathrm{Z}_{\text {hitung }}=\mathrm{r}_{\mathrm{s}} \sqrt{N-1}
$$

\section{Hasil dan Pembahasan \\ Peran Koperasi Produsen Karya Bhakti Mandiri}

Hasil penelitian pada Tabel 6 menunjukkan bahwa peran Koperasi KBM dalam memberikan layanan penyediaan dan pengadaan saprodi berada pada kategori berperan $50 \%$ dari total responden menyatakan Koperasi KBM berperan dalam penyediaan dan pengadaan saprodi. Peran dalam pembinaan dan pendampingan berkelanjutan berada pada kategori berperan $60 \%$ hal ini disebabkan karena tingkat intensitas pembinaan dan pendampingan dalam sebulan dilakukan minimal 2 kali waktu menyesuaikan keadaan anggota (peternak).

Layanan jasa pengolahan dan pemasaran menunjukkan bahwa Koperasi KBM berperan kategori rendah hingga sedang 40\%, sebagian anggota koperasi berusaha ternak dalam jumlah kecil (50-200 ekor) dan hasil ternak dijual hidup ke pasar tradisional atau konsumen langsung sehingga kurang membutuhkan jasa pengolahan dan pemasaran. Anggota yang menggunakan jasa Koperasi KBM untuk pengolahan dan pemasaran jumlah ternak > 200 ekor tiap periode produksi. Keberadaan Koperasi KBM sangat berperan $88 \%$ sebagai wahana menjalin kerjasama. Total skor keseluruhan peran Koperasi KBM rata-rata berada pada kategori berperan $52 \%$.

Tingkat peranan Koperasi KBM yang telah diberikan kepada anggota secara keseluruhan sudah menunjukkan peran yang cukup baik, walaupun masih banyak peluang dan potensi untuk meningkatkan peran koperasi ke arah layanan yang memberikan manfaat ekonomi dan sosial yang lebih baik. Koperasi yang mampu memberikan nilai manfaat akan memperoleh kepercayaan anggota masyarakat sekitar dan mampu memperluas ruang lingkup serta keragaman kegiatan layanan lainnya (Sibuea, 2015). 
Tabel 6. Distribusi responden terhadap penilaian peranan koperasi KBM

\begin{tabular}{llcccc}
\hline No & Indikator & Kategori & Skor & $\begin{array}{c}\text { Jumlah } \\
\text { Responden }\end{array}$ & Persentase \\
\hline 1 & Layanan penyediaan & Kurang berperan & 2 & 18 & $36 \%$ \\
& dan pengadaan saprodi & Berperan & $3-4$ & 25 & $50 \%$ \\
& & Sangat berperan & $5-6$ & 7 & $14 \%$ \\
& Jumlah & & $\mathbf{5 0}$ & $\mathbf{1 0 0 \%}$ \\
\hline 2 & Pembinaan dan & Kurang berperan & $4-5$ & 12 & $24 \%$ \\
& pendampingan & Berperan & $6-10$ & 30 & $60 \%$ \\
& berkelanjutan & Sangat berperan & $11-12$ & 8 & $8 \%$ \\
& Jumlah & & $\mathbf{5 0}$ & $\mathbf{1 0 0 \%}$ \\
\hline 3 & Layanan jasa & Kurang berperan & $3-4$ & 20 & $40 \%$ \\
& pengolahan dan & Berperan & $5-7$ & 20 & $40 \%$ \\
& pemasaran & Sangat berperan & $8-9$ & 10 & $20 \%$ \\
& Jumlah & & $\mathbf{5 0}$ & $\mathbf{1 0 0 \%}$ \\
\hline 4 & Wahana menjalin & Kurang berperan & 1 & 0 & $12 \%$ \\
& kerjasama & Berperan & 2 & 6 & $88 \%$ \\
& & 3 & 44 & $\mathbf{1 0 0 \%}$ \\
& Jumlah & Sangat berperan & 30 & $\mathbf{2 8 \%}$ \\
\hline 5 & Peranan Koperasi KBM & Kurang berperan & $10-15$ & 14 & $\mathbf{5 2 \%}$ \\
& & Berperan & $16-24$ & 26 & $\mathbf{1 0 0 \%}$ \\
\hline
\end{tabular}

Sumber: Data Primer diolah, 2019

\section{Pengembangan Usaha Ternak Ayam Kampung Pedaging di Kecamatan Bengalon}

Hasil penelitian tingkat pengembangan usaha ternak pada Tabel 7 menunjukkan bahwa pengembangan usaha ternak ayam kampung pedaging yang dilakukan oleh Koperasi KBM berada pada kategori berperan tinggi sebesar $60 \%$ dari total responden. Keterlibatan Koperasi KBM dalam upaya peningkatan permintaan produk kategori tinggi $48 \%$.

Tabel 7. Distribusi responden terhadap penilaian tingkat pengembangan usaha ternak ayam kampung pedaging di Kecamatan Bengalon

\begin{tabular}{llcccc}
\hline No & \multicolumn{1}{c}{ Indikator } & Kategori & Skor & $\begin{array}{c}\text { Jumlah } \\
\text { Responden }\end{array}$ & Persentase \\
\hline 1 & Meningkatkan & Rendah & 2 & 1 & 2 \\
& permintaan produk & Sedang & $3-4$ & 15 & $30 \%$ \\
& Jumlah & Tinggi & $5-6$ & 24 & $48 \%$ \\
& & & 50 & $\mathbf{1 0 0} \%$ \\
\hline 2 & Perbaikan sistem & Rendah & 2 & 1 & $2 \%$ \\
& produksi & Sedang & $3-4$ & 17 & $34 \%$ \\
& & Tinggi & $5-6$ & 32 & $64 \%$ \\
& Jumlah & & & $\mathbf{5 0}$ & $\mathbf{1 0 0 \%}$ \\
\hline 3 & Perbaikan sistem & Rendah & $3-4$ & 2 & $2 \%$ \\
& pemasaran & Sedang & $5-7$ & 28 & $56 \%$ \\
& & Tinggi & $8-9$ & 20 & $40 \%$ \\
& Jumlah & & & $\mathbf{5 0}$ & $\mathbf{1 0 0 \%}$ \\
\hline 4 & Tingkat & Rendah & $7-11$ & 1 & $2 \%$ \\
& Pengembangan usaha & Sedang & $12-16$ & 19 & $38 \%$ \\
& ternak ayam kampung & Tinggi & $17-21$ & 30 & $60 \%$ \\
& Jumlah & & & $\mathbf{5 0}$ & $\mathbf{1 0 0 \%}$ \\
\hline
\end{tabular}

Sumber: Data Primer diolah, 2020

Upaya perbaikan sistem produksi yang dilakukan berada pada kategori tinggi $64 \%$ hal ini disebabkan oleh sistem pemeliharaan dilakukan secara intensif dengan pemberian jamu alami sehingga mampu menjaga kualitas produksi. Perbaikan sistem pemasaran menunjukkan bahwa Koperasi KBM berperan kategori sedang $56 \%$ karena jumlah yang 
dipasarkan sangat tergantung dari jumlah ayam yang dipelihara sedangakan jumlah DOC menunggu pasokan dari luar daerah (kuantitas kurang terjamin). Keberadaan Koperasi KBM sangat berperan secara total skor keseluruhan rata-rata berada pada kategori tinggi $60 \%$ dari total responden. Peranan koperasi semakin besar dan kuat apabila mendapat dukungan dari pihak terkait utamanya anggota koperasi, masyarakat sekitar dan pemerintah (Wahyudi, 2017).

\section{Hubungan antara Peran Koperasi Karya Bhakti Mandiri dengan Pengembangan Usaha Ternak Ayam Kampung Pedaging di Kecamatan Bengalon}

Hasil penelitian yang dilakukan untuk mengetahui peran Koperasi KBM yang terdiri dari kegiatan-kegiatan yang dilaksanakan meliputi layanan penyediaan dan pengadaan saprodi, pembinaan dan pendampingan berkelanjutan, layanan jasa pengolahan dan pemasaran ayam kampung serta wahana menjalin kerjasama. Tingkat pengembangan usaha ternak ayam kampung pedaging di Kecamatan Bengalon yang meliputi kegiatan meningkatkan permintaan produk, perbaikan sistem produksi dan perbaikan sistem pemasaran. Analisis chi-square $\left(x^{2}\right)$ dilakukan dengan membandingkan $X^{2}$ hitung dengan $X^{2}$ tabel. Analisis korelasi rank spearman dilakukan untuk mengetahui keeratan hubungan antara peran Koperasi KBM terhadap tingkat pengembangan usaha ternak ayam kampung pedaging di Kecamatan Bengalon dengan melihat nilai $r_{s}$ (Siregar, 2013).

\section{Uji Chi Square SPSS}

Hasil analisis yang dilakukan menunjukkan bahwa Koperasi KBM berperan dalam pengembangan usaha ternak ayam kampung pedaging sehingga melalui peran Koperasi KBM yang baik dapat meningkatkan pengembangan usaha ternak ayam kampung pedaging. Hal tersebut diketahui dari hasil perhitungan $X^{2}$ hitung sebesar 31,290 dibandingkan dengan $X^{2}$ tabel $(\alpha=0,05)$ sebesar 9,488. Kesimpulan apabila $X^{2}$ hitung $>X^{2}$ tabel $(\alpha=0,05)$ maka Ho ditolak dan Ha diterima berarti terdapat hubungan antara peran Koperasi KBM dengan tingkat pengembangan usaha ternak ayam kampung pedaging di Kecamatan Bengalon.

Tabel 8. Crosstabulasi PKKBM * PUTAK

\begin{tabular}{llccrr}
\hline & & \multicolumn{1}{c}{ PUTAK } & Total \\
\cline { 3 - 5 } & & Rendah & Sedang & Tinggi & \\
\hline \multirow{3}{*}{ PKKBM } & Kurang Berperan & 1 & 13 & 0 & 14 \\
& Berperan & 0 & 6 & 20 & 26 \\
& Sangat Berperan & 0 & 0 & 10 & 10 \\
\hline Total & & 1 & 19 & 30 & 50 \\
\hline
\end{tabular}

Sumber: Data Primer diolah (2020) 
Tabel 9. Uji chi square

\begin{tabular}{lccc}
\hline & Nilai & df & Asymp. Sig. (2-sided) \\
\hline Chi Square Pearson & $31,290^{\mathrm{a}}$ & 4 &, 000 \\
Rasio Likelihood & 39,946 & 4 &, 000 \\
Linear-by-Linear Association & 25,891 & 1 &, 000 \\
N of Valid Cases & 50 & &
\end{tabular}

\section{Uji Korelasi Rank Spearmans SPSS}

Sampel $N>30$ (Sampel 50 orang) maka distribusi persampelan menggunakan distribusi normal dengan statistik uji Z (Siregar, 2013).

Tabel 10. Uji Korelasi Rank Spearmans

\begin{tabular}{|c|c|c|c|c|}
\hline & & & PKKBM & PUTAK \\
\hline \multirow{6}{*}{ Spearman's rho } & \multirow{3}{*}{ PKKBM } & Koefisien Korelasi & 1,000 &, $748^{*}$ \\
\hline & & Sig (2 sisi) & . &, 000 \\
\hline & & $\mathrm{N}$ & 50 & 50 \\
\hline & \multirow{3}{*}{ PUTAK } & Koefisien Korelasi &, $748^{* \star}$ & 1,000 \\
\hline & & Sig. (2 sisi) &, 000 & \\
\hline & & $\mathrm{N}$ & 50 & 50 \\
\hline
\end{tabular}

**. Korelasi signifikan 0.01 level (2-sisi)

Bentuk hipotesis:

HO : Tidak ada hubungan yang erat antara Peran Koperasi KBM dengan Pengembangan usaha ternak ayam kampung pedaging di Kec. Bengalon

$\mathrm{Ha}$ : Terdapat hubungan yang erat antara Peranan Koperasi KBM dengan Pengembangan usaha ternak ayam kampung pedaging di Kecamatan Bengalon

1. Hipotesis statistik:

$\mathrm{HO}: \mathrm{r}_{\mathrm{s}}=0$

$\mathrm{Ha}: r_{\mathrm{s}}>0, r_{\mathrm{s}}<0, r_{\mathrm{s}} \neq 0$

2. Kaidah Pengujian:

Jika $Z_{\text {hitung }}>Z_{\text {tabel }}$, maka $\mathrm{HO}$ ditolak

3. Menghitung $Z_{\text {hitung }}$ dan $Z_{\text {tabel }}$

Menghitung $Z_{\text {hitung }}$

Rumus: $Z_{\text {hitung }}=\mathrm{r}_{\mathrm{s}} \sqrt{N-1}$

$$
=0,748 \sqrt{50-1}=5,236
$$

4. Menentukan $Z_{\text {tabel }}$

Karena uji 2 sisi (two tail) maka $\alpha / 2=0,1 / 2=0,05$

$Z_{\text {tabel }}=1-0,05=0,95$

Nilai 0,95 tabel kurva normal $=1,645$

5. Membandingkan $Z_{\text {hitung }}$ dan $Z_{\text {tabel }}$

Jika $Z_{\text {hitung }}>Z_{\text {tabel }}$ maka $\mathrm{HO}$ ditolak

$Z_{\text {hitung }}=5,236>Z_{\text {tabel }}=1,645$ 
6. Mengambil Keputusan

Ada hubungan yang erat antara Peran Koperasi KBM dengan Usaha ternak ayam kampung pedaging di Kecamatan Bengalon.

Peran Koperasi KBM pada tingkat yang baik mampu meningkatkan pengembangan usaha ternak ayam kampung yang dijalankan oleh anggotanya. Hal tersebut menunjukkan bahwa peranan Koperasi KBM berpengaruh signifikan terhadap tingkat pengembangan usaha ternak ayam kampung dilihat dari hasil perhitungan $Z_{\text {hitung }}$ sebesar 5,236 dibandingkan $Z_{\text {tabel }(\alpha=0,5)}$ sebesar 1,645. Kesimpulan apabila $Z_{\text {hitung }}>Z_{\text {tabel }}$ $(\mathrm{a}=0,5)$ maka Ho ditolak dan Ha diterima berarti terdapat hubungan yang kuat antara peran Koperasi KBM dengan tingkat pengembangan usaha ternak ayam kampung di Kecamatan Bengalon.

Hubungan antara Peran Koperasi KBM dengan tingkat pengembangan usaha ternak ayam kampung pedaging di Kecamatan Bengalon berada pada kategori kuat $\left(r_{\mathrm{s}}=\right.$ 0,748 ). Posisi hubungan yang kuat ini disebabkan oleh adanya peranan Koperasi KBM pada tingkat yang baik akan mampu meningkatkan pengembangan usaha ternak yang baik pula bagi anggota peternak dan masyarakat di sekitar wilayah kerja Koperasi KBM.

\section{Kontribusi Koperasi KBM terhadap Upaya Pengembangan Usaha Ternak Anggota}

Besarnya kontribusi Koperasi KBM dalam usaha ternak ayam anggotanya di Kecamatan Bengalon menurut Siregar (2013) dapat dihitung dengan rumus Koefisien Determinasi $(K D)=\left(r_{s}\right)^{2} \times 100 \%$

$$
\begin{aligned}
& =(0,748)^{2} \times 100 \% \\
& =55 \%
\end{aligned}
$$

Sumbangan keterlibatan Koperasi KBM dalam upaya peningkatan pengembangan usaha ternak anggotanya sebesar 55\% berdampak baik di wilayah Kecamatan Bengalon. Upaya pengembangan usaha ke depan yang perlu dilakukan dan dikembangkan diantaranya kontribusi peningkatan populasi, produksi, produktivitas dan efisiensi usaha dalam beternak sehingga perlu dukungan teknologi perbaikan kualitas dan kuantitas bibit serta pakan juga pencegahan dan penanggulangan penyakit (Suryana, 2017).

\section{Kesimpulan}

Peran Koperasi KBM rata-rata berperan 52\% kategori sedang dan tingkat pengembangan usaha ternak ayam kampung rata-rata 60\% kategori tinggi. Terdapat hubungan yang erat antara peranan Koperasi KBM terhadap pengembangan usaha ayam pedaging hasil analisis uji Chi Square $x^{2}$ hitung $=31,290$ dibandingkan $x^{2}$ tabel $(\alpha=0.05)=$ 9,488 berpengaruh signifikan $Z_{\text {hitung }}=5,236$ dibandingkan $Z_{\text {tabel }}(\alpha=0.5)=1,645$. Keeratan hubungan berada pada kategori kuat $\left(r_{s}=0,748\right)$. Koperasi KBM 55\% memberikan 
sumbangan kontribusi nyata terhadap upaya peningkatan pengembangan usaha ayam kampung pedaging anggotanya di Kecamatan Bengalon.

\section{Daftar Pustaka}

Agustia, D., Kusnadi, N., \& Harianto, H. (2017). Studi Empiris Perilaku Usaha Koperasi Pertanian: Kasus Koperasi Di Dataran Tinggi Gayo, Provinsi Aceh. Jurnal Manajemen Dan Agribisnis, 14(1), 12-21. https://doi.org/10.17358/jma.14.1.12

BPS Kutai Timur. (2018). BPS Kutai Timur dalam Angka 2018. Katalog BPS: 1102001.6404. BPS Kutai Timur, Sangatta.

Fitriani, F. (2015). Penguatan kapasitas kelembagaan gapoktan melalui pembentukan koperasi pertanian. Masyarakat, Kebudayaan Dan Politik, 28(2), 63. https://doi.org/10.20473/mkp.v28i22015.63-69

Heriyono. (2012). Peran Koperasi Dalam Pengembangan Perekonomian Rakyat. Jurnal EKONOMI, 1(1), 40-51.

IKAPI. (2013). Undang-undang Perkoperasian. Bandung: Fokusmedia.

Musthofa, I., \& Kurnia, G. (2018). Prospek Penerapan Sistem Corporate Farming. Jurnal AGRISEP, 16(1), 11-12. https://doi.org/10.31186/jagrisep.17.1.11-12.

Sastrawidjadja, M. S., \& Adam, R. C. (2015). Langkah Menuju Konglomerasi Koperasi di Indonesia. Padjadjaran Jurnal IImu Hukum, 2(2), 209-231.

Sibuea, B. M. (2015). Analisis Kontribusi Koperasi Pertanian dalam Meningkatkan Pendapatan Petani di Kabupaten Langkat. Jurnal UMSU, 1(1). Retrieved from http://jurnal.umsu.ac.id/index.php/kumpulandosen/article/view/655

Siegel, S. (2008). Statistik Non Parametrik Untuk IImu-ilmu Sosial. Jakarta: Gramedia.

Siregar, S. (2013). Metode Penelitian Kuantitatif: dilengkapi Perbandingan Perhitungan Manual dan SPSS. Jakarta: Prenadamedia Group.

Sugiyono. (2017). Statistik Non Parametrik untuk Penelitian. Bandung: Alfabheta.

Suparman. (1995). Statistik Sosial. Jakarta: Raja Grafindo.

Suryana. (2017). Pengembangan Ayam Kampung Unggul Balitbangtan (KUB) di Kalimantan Selatan. Jurnal WARTAZOA, 27(1), 45-52. https://doi.org/http: //dx.doi.org/10.14334/wartazoa.v27i1.130345.

Susilo, E. (2013). Peran Koperasi Agribisnis dalam Ketahanan Pangan di Indonesia. Jurnal Dinamika Ekonomi Dan Bisnis, 10(1), 1-10. Retrieved from https://ejournal.unisnu.ac.id/JDEB/article/download/28/39

Syahza, A., \& Indrawati, H. (2010). Pemberdayaan Koperasi Berbasis Agribisnis Di Daerah Pedesaan. Sosiohumaniora, 12(3), 207-220. https://doi.org/10.24198/sosiohumaniora.v12i3.11551 
Wahyudi, J. (2017). Kontribusi Koperasi Dalam Upaya Pencapaian Tujuan-Tujuan Pembangunan Berkelanjutan ( Studi Kasus KUD Bahagia Kabupaten Pati ). The 6th University Research Colloquium, 9-16.

Wahyuningsih, S. (2007). Pengembangan agribisnis ditinjau dari kelembagaan. MEDIAGRO, 3(1).

Widjajani, S., \& Hidayati, S. N. (2014). Membangun koperasi pertanian berbasis anggota di era globalisasi. Jurnal Maksipreneur: Manajemen, Koperasi, Dan Entrepreneurship, 4(1), 98-115. 